\title{
Relative Crash Involvement Ratio Associated with Different Sources of Young Drivers' Distraction
}

\author{
Hana Naghawi ${ }^{1} \&$ Shatha Aldalain ${ }^{2}$ \\ ${ }^{1}$ Civil Engineering Department, School of Engineering, The University of Jordan, Amman, Jordan \\ ${ }^{2}$ Civil Engineering Department, College of Engineering, Al-Hussein Ben Talal University, Ma'an, Jordan \\ Correspondence: Hana Naghawi, Civil Engineering Department, School of Engineering, The University of Jordan, \\ Amman 11942, Jordan. Tel: 962-6535-5000. E-mail: hana_naghawi@yahoo.com \\ Received: February 16, $2018 \quad$ Accepted: February 28, $2018 \quad$ Online Published: April 17, 2018 \\ doi:10.5539/mas.v12n5p1 URL: https://doi.org/10.5539/mas.v12n5p1
}

\begin{abstract}
This paper aims to identify crash risk factors associated with young drivers' distractions. Many factors were implicated including using mobile phones while driving or driving with passengers. Data needed for this study were collected from an online questionnaire survey. Beside young drivers' distraction data, records on drivers' demographics including age, gender and educational level were collected. Safety-related data on seat belt use were also collected. Each of the variables, contributing to young drivers' distraction, safety, and educational level, was sorted into four categories according to young driver age ( $\leq 18,19-22,23-26$, and 27-30 years old). The Relative Crash Involvement Ratio (RCIR) was estimated using the Quasi Induced Exposure Method (QIEM) using Microsoft Excel 2007. The results were then exported to the Statistical Package for Social Science Version 19 software. Paired t-test and ANOVA analysis were used to find the statistical significance in the RCIR values. Among the general findings, five outcomes were most prominent. The higher the educational level, the less likely young drivers would get involved in a crash. Young drivers $\leq 18$ years old were almost 4.5 times more likely to get involved in a crash when 3 passengers travelled with them compared to 27-30 year-old drivers. Young drivers of all age groups were more likely to get involved in a crash when using mobile phones. Crash risk was reduced by up to $83 \%$ when young drivers stopped using their mobile phone while driving. Crash risk was reduced by up to $93.43 \%$ when young drivers used seat belt while driving. Finally, countermeasures to improve young drivers' safety were proposed.
\end{abstract}

Keywords: young drivers safety, young drivers distraction, mobile phone use, passengers, seat belt use, traffic crashes, Quasi Induced Exposure Method, QIEM, Relative Crash Involvement Ratio, RCIR

\section{Introduction}

The problem of traffic crashes is one of the most important and serious problems facing communities around the world. The world health organization (WHO, 2015) statistics indicated that every year almost 1.24 million people die as a result of road traffic crashes and 20 to 50 million more people are injured with many left disabled. It also indicated that 91 percent of traffic fatalities in the world take place in the developing countries. By 2020 road traffic crashes are predicted to cause 1.9 million deaths annually, as a result traffic crashes are becoming the leading cause of death worldwide (WHO, 2015). Crashes can be contributed to many factors such as speeding and distractions. Drivers' distraction has been found to be the contributing factor to up to 25 percent of road crashes (McEvoy at el., 2007). Drivers' distraction was defined by Young and Regan (2007) as what occurs when driver's attention is shifted away from the driving task by an object, activity, event, or passengers, to a degree that the driver no longer is able of perform the driving task safely. Jordan, with its vast population growth rate, seriously suffers from traffic crashes problem. Table 1 shows the evolution of people and vehicles in Jordan between the years 1971 and 2015 (JTS, 2015).

Table 1. Evolution of People and Vehicles in Jordan between 1971 and 2015

\begin{tabular}{cccc}
\hline Year & Population & Registered Vehicles & Vehicles ownership \\
\hline 1971 & 1.57 million & 26,000 & Veh $/ 58$ persons
\end{tabular}


Source: JTI, 2015

The Table shows that at the end of 2015, population in Jordan reached 9.53 million with $507 \%$ population growth between 1971 and 2015. It also shows that the number of registered vehicles in Jordan has significantly increased from 26,000 in 1971 to 1,412,817 in 2015 and the vehicle ownership reached vehicle per 7 persons, as a result traffic volume and vehicle miles travel have significantly increased leading to a significant increase in traffic crashes. Jordan Traffic Institute (2015) reported that crashes that took place in Jordan in the year 2015 were 111,057 crashes. They resulted in 608 fatalities, 160 of them, more than $26 \%$, were among young drivers, it also resulted in 16,139 injuries, 5944 of them, more than $36 \%$, were also among young drivers. Statistics of JTI (2015) indicated that the percentage of young drivers involved in traffic crashes to registered drivers is $19 \%$ which is the highest percentage compared to other driver's age groups. Naghawi (2018) used the negative binominal regression technique to develop crash severity prediction model in Jordan. The model results indicated that severe crashes decreased significantly as the age of both male and female drivers increased. Jadaan et al. (2013) developed road fatality prediction model under Jordanian conditions and based on aggregated data, they expected that by 2020, the number of road crash fatalities will reach 1054 fatality, 276 of them will be among young drivers. Young drivers' safety in Jordan was studied by Naghawi (2017), different young drivers' crash contributing factors including driver's age, gender, number of vehicles involved, highway class, severity of crash, environmental conditions and time of crash were studied. To the best of authors' knowledge, the issue of young drivers' distraction in Jordan as a crash contributing factor has not been addressed yet. The objective of this paper is to identify young drivers' crash risk factors especially factors associated with young drivers' distractions. To achieve this purpose, the Quasi Induced Exposure Method was used, data were collected using an online questionnaire survey for young drivers of age 18 years old or younger to 30 years old. The Relative Crash Involvement Ratio was calculated only for single and two vehicle crashes. Also, in this paper, some countermeasures to enhance young drivers' safety were proposed.

\section{Literature Review}

A review on young drivers' crash contributing factors and an overview on the Quasi Induced Exposure Method are presented bellow.

\subsection{Young Drivers' Crash Contributing Factors}

The Organization for Economic Co-operation and Development and European Conference of Ministers of Transport (ECMT, 2006) explained that young drivers' lack of experience is the most important factor in increasing young drivers crash risk, this doesn't only affect young drivers, but also passengers and road users. The National Highway Traffic Safety Administration (NHTSA, 2010) stated that young drivers of age 15-20 years old are more prone to crashes because of their lack of experience, they also reported that reducing alcohol involvement can significantly reduce the proportion of young drivers fatal and injury crashes. Tefft et at. (2013) illustrated that young drivers, $16-17$ years old, crash risk increased by $44 \%$ when a passenger under the age of 21 is in the vehicle, they also found that the risk of crashes increased by $50 \%$ and $75 \%$ when two passengers and three passengers are in the vehicle respectively. Chen et al. (2000) studied the effect of young drivers' gender and number of passengers on young drivers' fatal crash risk. They found that male drivers have higher propensity to get involved in a crash than female drivers, they also found that the risk of fatal crash increased significantly for 16-17 years old drivers when driving with passengers. AL-Farraj (2007) found that drivers 2534 years old use mobile phone on an average of 10-15 times per day while driving, few of them believe that crashes can be caused by using mobile phones while driving. Regan et al. (2003) showed that using mobile phone while driving increases driver's mental workload, impairs judgment, slows reaction times, reduces awareness of surroundings, and increases the risk of being involved in a crash by up to 4 times.

\subsection{Quasi Induced Exposure Method}

The Quasi Induced Exposure method (QIEM) was first developed by Thorpe back in 1967. He developed formulas that estimate the relative likelihood of the driver's involvement in a crash as the ratio between number of driver's involvement in a crash to exposure. Exposure depends on single and multiple vehicles, without distinction between at fault and non at fault driver's involvement in crashes. After that, Carr (1970) introduced the idea of being able to identify the driver responsible for a crash in a multiple vehicle crash depending on police reports investigations. Lyles et at. (1991) demonstrated that the center of attention in the QIEM was the identification of the driver at fault in crashes. Mengert (1982) revealed that the QIEM can analyze all spatial and 
temporal data, this type of analyses cannot be carried out by traditional methods of exposure such as vehicle mile travel because of the difficulty of collecting data for this method. Due to the accuracy in estimating crash risks of the QIEM method, it has been increasingly popular in traffic safety analysis. Hing et al. (2003) used the QIEM for quantifying old drivers' crash tendency in Kentucky. Four years of older drivers' crash data was used. It was found that the presence of two or more passengers negatively impact the probability that 75 years old drivers get involved in a crash. Naghawi (2017) studied young drivers' safety in Jordan using the QIEM. The study illustrated that young male drivers have higher tendency to get involved in a crash than young female drivers, young drivers are more likely to cause a crash during weekdays than weekends, young drivers are exposed to major injury when involved in a single vehicle crash while they are exposed to fatal crashes when involved in a two vehicle crash. Also it was found that young drivers' crash risk increased under poor environmental conditions. Kirk and Stamatiadis (2001) used the QIEM to quantify young drivers' crash tendency. The study revealed that for all crashes, there is a general trend of decreasing involvement with increasing age. Fohr et al. (2005) employed the QIEM to evaluate the effectiveness of the graduated driver licensing program in the USA. Yan et al. (2005) implemented the QIEM in a study to specify crash types such as rear end crashes. Preusser et al. (1998) used the QIEM to study the effect of young passengers on young drivers' fatal crash risk. It was found that young drivers' fatal crash risk significantly increased when traveling with young passengers. Rice et al. (2003) investigated young drivers' crash risk in California using the QIEM, it was found that carrying male passengers or mixed gender passengers was significantly associated with an increase in crash risk. Aldridge et al. (1999) applied the QIEM to study the effect of passengers on young drivers' crash risk depending on police reported crash data in Kentucky for the years $1994-1996$. They found that young drivers' have higher probability of getting involved in a crash when traveling with peers.

\section{Data Collection}

Data needed for this study were obtained from a questionnaire survey. The survey was conducted using an online questionnaire sent by Google Drive. The survey was carried out between the $20^{\text {th }}$ of September and $20^{\text {th }}$ of October 2015. The survey was written in Arabic and English because it targeted all young drivers' educational levels. 5270 responded, 3630 were analyzed because only single and two vehicle crashes were considered. $43 \%$ of the survey respondents were female drivers. The questionnaire included a total of eight questions; three of them were about drivers' demographic characteristics including drivers' gender, age and educational level. Two questions were about young drivers' distraction during crashes including: number of passengers in the vehicle and using mobile phone while driving. One question was about young drivers' safety behavior in particular the use seat belt while driving. Two questions were needed to calculate the RCIR including number of vehicles involved and whether the driver was at fault or not at fault in the crash.

\section{Methodology}

Young drivers were grouped into four age groups including (18 or younger, 19-22, 23-26 and 27-30). Then crash data were sorted according to young drivers' age groups and according to young drivers' educational level, number of passengers in the vehicle, mobile phone use and seat belt use while driving. The QIEM was used to calculate the RCIR using Microsoft Excel 2007. Then the results were exported from excel sheets to the Statistical Package for Social Science Version 19 (SPSS 19) software. The Paired t-test and the one way analysis of variance (ANOVA) tests, at 95 percent confidence level, were used to find the statistical significance in the differences among the RCIR values. The RCIR calculations were only assigned for single and two vehicle crashes because most crashes in Jordan are single and two vehicle crashes. Single vehicle crashes were all classified as at fault crashes, while the two vehicle crashes were classified as at fault crashes and or at fault crashes.

The RCIR can be calculated as the ratio of the percentage of at fault drivers in a specific subgroup to the percentage of the not at fault drivers from the same subgroup. The denominator is the percentage of not at fault drivers in two vehicle crashes, and the numerator is the corresponding percentage of at fault drivers in single and/or two vehicle crashes. If the RCIR value is greater than 1.0 for the specific subgroup of drivers, it is more likely to cause a crash, and if it is less than 1.0, the drivers in the specific subgroup are less crash prone. RCIR equation can be written as shown in equation (1):

$$
\text { RICR }=\frac{\% \text { of drivers at }- \text { fault in single } / \text { two }- \text { vehicle crashes for specific group }}{\% \text { of drivers not at }- \text { fault in two-vehicle crashes for specific group }}
$$

Sample RCIR calculation is illustrated below: 
- Number of young drivers, 18 years old and younger, who use mobile phone while driving and was involved in a single vehicle crash is 301 .

- Total number of young drivers, 18 years old and younger, who was involved in a single vehicle crash is 798.

- Number of not at fault young drivers, 18 years old and younger, who use mobile phone while driving and was involved in a two vehicle crash is 107 .

- Total number of not at fault young drivers, 18 years old and younger, who was involved in a two vehicle crash is 1169 .

Using equation (1), the RCIR can be calculated as follows:

$\mathrm{RICR}=\frac{302 / 798}{107 / 1169}=4.12$

\section{Results and Discussions}

The RCIR values were calculated for single and two vehicle crashes separately for the four age groups and according to young drivers' educational level, number of passengers in the vehicle, mobile phone use and seat belt use.

\subsection{RCIR by Educational Level}

Young drivers' educational level was divided into three levels including: primary school, high school and college degree. The RCIR for single and two vehicle crashes was calculated for each educational level and driver's age as shown in Table 2 . The table shows that the higher the educational level, the less likely young drivers would get involved in a traffic crash. The percent reduction in crash risk ranges between $62.50 \%$ and $79.90 \%$ in single vehicle crashes and it ranges between $49.54 \%$ and $62.69 \%$ in two vehicle crashes for young drivers having college degree when compared to young drivers having primary school education. This can be explained by the fact that the higher the educational level the higher the maturity level.

Table 2. Relative Crash Involvement Ratio by Educational Level

\begin{tabular}{ccccc}
\hline & \multicolumn{5}{c}{ Single Vehicle RCIR } \\
\hline Driver's Age & Primary School & High school & College Degree & P-value \\
$\leqslant 18$ & 1.00 & 0.45 & - & 0.105 \\
$19-22$ & 1.99 & 0.70 & 0.53 & \\
$23-26$ & 2.00 & 0.95 & 0.75 & \\
$27-30$ & 2.14 & 0.43 & 0.43 & 0.032 \\
\hline \multirow{5}{5}{$\leqslant$} & Two Vehicle RCIR & \\
$19-22$ & 1.00 & 0.57 & - & \\
$23-26$ & 1.93 & 0.89 & 0.72 & \\
$27-30$ & 1.53 & 1.11 & 0.55 & \\
\hline
\end{tabular}

The statistical significance in the RCIR values among the three educational levels for single and two vehicle crashes was tested using the one way ANOVA and assuming the following null and alternative hypotheses:

$H_{0}$ : The RCIR values among the three educational levels are equal.

$H_{1}$ : The RCIR values among the three educational levels are different.

It was found that there were significant differences in the RCIR among the three educational levels in the two vehicle crashes while there were no significant differences among the three educational levels in the single vehicle RICR. The statistically significant results are shown in italic font in the right most column in Table 2.

\subsection{RCIR by Number of Passengers in the Vehicle}

Passengers in the vehicle were classified into four groups: solo (no passengers), one passenger, two passengers and three or more passengers. The RCIR for single and two vehicle crashes was calculated for each passenger group and driver's age as shown in Table 3. It can be seen that the older young drivers get, the less likely they become involved in a crash regardless of the number of passengers traveling with them. This can be related to 
the experience gained by young drivers with age. Also, it can be seen that young drivers 18 years old or younger are almost 4.5 times more likely to get involved in a crash when 3 or more passengers travel with them compared to $27-30$ years old age group.

Table 3. Relative Crash Involvement Ratio by Number of Passengers

\begin{tabular}{cccccc}
\hline & \multicolumn{5}{c}{ Single Vehicle RCIR } \\
\hline Driver's Age & Solo & One Passenger & Two Passengers & $\geqslant 3$ Passengers & P-value \\
$\leqslant 18$ & 1.23 & 1.41 & 1.23 & 4.43 & 0.702 \\
$19-22$ & 0.91 & 1.29 & 0.85 & 0.61 & 0.57 \\
$23-26$ & 0.37 & 0.98 & 0.44 & 0.80 & \\
$27-30$ & 0.51 & 0.40 & 0.40 & 1.38 \\
\hline \multicolumn{6}{c}{ Two Vehicle RCIR } \\
\hline 18 & 0.94 & 1.55 & 1.94 & 0.000 \\
$19-22$ & 0.66 & 1.19 & 0.69 & 1.24 & \\
$23-26$ & 0.93 & 1.05 & 0.62 & 1.08 & \\
$27-30$ & 0.81 & 0.62 & 0.51 & 0.26 & \\
\hline
\end{tabular}

The statistical significance in the RCIR among the four passenger groups for both single and two vehicle crashes was tested using the one way ANOVA. The following null and alternative hypotheses were assumed:

$H_{0}$ : The RCIR values among the four passenger groups are equal.

$H_{1}$ : The RCIR values among the four passenger groups are different.

The right most column of Table 3 shows the results. It can be seen that there were significant differences in the two vehicle RCIR among the four passenger groups, while there were no significant differences among single vehicle RCIR for the four passenger groups. The statistically significant results are shown in italic font.

\subsection{RCIR by Mobile Phone Use While Driving}

Table 4 shows the impact of mobile phone use on young drivers' crash causing tendency. The RCIR for single and two vehicle crashes was calculated when using and when not using mobile phone while driving. The table also shows the percent reduction in crash risk when young drivers stop using mobile phone while driving. The statistical significance in the RCIR when using or not using mobile phone while driving was tested, for single and two vehicle crashes, using the Paired t-test and shown in the right most column of the table assuming the following null and alternative hypotheses:

$H_{0}$ : The RCIR when using or not using mobile phone are equal.

$H_{1}$ : The RCIR when using or not using mobile phone are different.

Table 4 shows that young drivers of all age groups are more likely to get involved in a single and two vehicle crashes when using mobile phone while driving. The percent reduction in the crash risk ranges between $19.63 \%$ and $83.30 \%$ in single vehicle crashes and it ranges between $13.64 \%$ and $69.82 \%$ in two vehicle crashes when young drivers' stop using mobile phone while driving. Also, it can be seen that there were significant differences between RCIR when using or not using mobile phone while driving for both single and two vehicle crashes.

Table 4. Relative Crash Involvement Ratio by Mobile Phone Use

\begin{tabular}{ccccc}
\hline & \multicolumn{5}{c}{ Single Vehicle RCIR } \\
\hline Driver's Age & Using Mobile Phone & Not Using Mobile Phone & \% Reduction & P-value \\
$\leqslant 18$ & 4.12 & 0.69 & 83.30 & \\
$19-22$ & 1.25 & 0.18 & 65.60 & 0.028 \\
$23-26$ & 1.41 & 0.34 & 75.89 & \\
$27-30$ & 1.07 & 0.86 & 19.63 & \\
\hline \multicolumn{5}{c}{ Two Vehicle RCIR } \\
$18-22$ & 2.75 & 0.83 & 69.82 & \\
$23-26$ & 1.12 & 0.60 & 46.43 & \\
$27-30$ & 1.05 & 0.97 & 7.62 & \\
\hline
\end{tabular}




\subsection{RCIR by Seat Belt Use}

Table 5 shows the impact of seat belt use on young drivers' crash causing tendency. The RCIR for single and two vehicle crashes was calculated when using and when not using seat belt while driving. The table also shows the percent reduction in crash risk when young drivers use seat belt while driving.

Table 5. Relative Crash Involvement Ratio by Seat Belt Use

\begin{tabular}{ccccc}
\hline & \multicolumn{5}{c}{ Single Vehicle RCIR } \\
\hline Driver's Age & Using Seat Belt & Not Using Seat Belt & \% Reduction & P-value \\
$\leqslant 18$ & 0.8 & 1.07 & 25.23 & \\
$19-22$ & 0.64 & 1.36 & 52.94 & 0.098 \\
$23-26$ & 0.36 & 1.68 & 78.57 & \\
$27-30$ & 0.19 & 2.89 & 93.43 & \\
\hline \multicolumn{5}{c}{ Two Vehicle RCIR } \\
$19-22$ & 0.95 & 1.34 & 29.10 & \\
$23-26$ & 0.5 & 1.50 & 66.67 & \\
$27-30$ & 0.65 & 1.38 & 52.90 & \\
\hline
\end{tabular}

Table 5 shows that young drivers of all age groups are more likely to get involved in a single and two vehicle crashes when not using seat belt while driving. The percent reduction in crash risk ranges between $25.23 \%$ and $93.43 \%$ in single vehicle crashes and it ranges between $29.10 \%$ and $66.67 \%$ in two vehicle crashes when young drivers use the seat belt while driving.

The statistical significance in the RCIR when using or not using seat belt while driving was tested using the Paired t-test and shown in the right most column of Table 5. The statistically significant results are shown in the table in italic font. The following null and alternative hypotheses were used for this comparison:

$H_{0}$ : The RCIR when using or not using seat belt are equal.

$H_{1}$ : The RCIR when using or not using seat belt are different.

It was found that there were no statistical differences in the RCIR when using or not using seat belt for single vehicle crashes, while there were statistical differences in the RCIR when using or not using seat belt for two vehicle crashes.

\section{Countermeasures}

Dealing with the elevated levels of young drivers crash risk is a fundamental element to reduce the impact of road traffic crashes on human health. However, the causes of this problem are well known and are related mainly to young drivers' distraction and lack of experience. The major challenge to highway planners remains in identifying and implementing appropriate countermeasures. The proposed countermeasures for addressing young drivers' problem focus mainly on decreasing exposure and enhancing traffic safety educational programs such as: increasing licensing age for solo driving to 21 years old as the minimum licensing age for solo driving in Jordan is 18 years old, increase public awareness of the problem by implementing educational programs and/or courses on safe driving for children at schools as drivers attitudes are formed before the age at which persons start legally driving a vehicle, also by highlighting the problem by traffic officials on media. Training should not only focus on vehicle control and maneuvering, but also on understanding the factors that increase crash risk and on advancing drivers knowledge and experience. Implementing graduated driver licensing (GDL) program, GDL is mainly designed to address the inexperience element of young drivers' crash risk in which experience is gained in stages of progressively increased complexity of driving situations. It typically divides newly drivers in three phases: learner, conditional, and fully licensed drivers. Effective enforcement should be executed in which young drivers might lose their driving license or undergo additional training if they do not obey traffic rules such as speeding, using mobile phone, or not using seat belt while driving.

\section{Summary and Conclusion}

Young drivers have higher risk to get involved in vehicle crashes than any other ages groups. Drivers' distraction has been found to be an important factor leading to young drivers' crashes. This paper aimed to identify crash risk associated with young drivers' educational level, distractions and seat belt use while driving. Data were collected from an online questionnaire survey. The survey was conducted between the $20^{\text {th }}$ of September and $20^{\text {th }}$ 
of October 2015. The survey was written in Arabic and English because it targeted all young drivers' educational levels. The questionnaire included a total of eight questions; three of them were about drivers' demographic characteristics including drivers' gender, age and educational level. Two questions were about young drivers' distraction including: number of passengers in vehicle and using mobile phone while driving. One question was about young drivers' safety behavior in particular the use seat belt while driving. Two questions were needed to calculate the Relative Crash Involvement Ratio including number of vehicles involved and whether the driver was at fault or not at fault in the crash. To analyze the data, data were sorted according to young drivers' age groups $(\leq 18,19-22,23-26$ and 27-30) and according to educational level, number of passengers in vehicle, mobile phone use while driving and seat belt use. The Relative Crash Involvement Ratio was estimated using the Quasi Induced Exposure Method using Microsoft Excel 2007, then the results were exported from excel sheets to the Statistical Package for Social Science Version 19 (SPSS 19) software. Paired t-test and ANOVA analysis were used to find the statistical significance among the RCIR values. Among the general findings, it was found that the higher the educational level the less likely young drivers would get involved in a traffic crash, the older young drivers get the less likely they get involved in a traffic crash regardless of the number of passengers traveling with them. Also, it was found that young drivers of all age groups are more likely to get involved in a traffic crash when using mobile phone. The percent reduction in crash risk was up to $83.30 \%$ when young drivers stop using mobile phone while driving. Finally, regarding young drivers' seat belt use while driving, it was found that young drivers of all age groups are more likely to get involved in a crash when not using seat belt while driving. The results suggested the use of countermeasures to improve young drivers' safety by decreasing exposure and enhancing traffic safety educational programs. Countermeasures which focused on decreasing exposure are such as increasing licensing age for solo driving and implementing graduated driver licensing program. Countermeasures which focused on educational programs are such as training, increasing public awareness of the problem and effective enforcement.

\section{References}

Aldridge, B., Himmler, M., Aultman-Hall, L., \& Stamatiadis, N. (1999). Impact of Passengers on Young Driver Safety. Transportation Research Record 1693, 25-30.

AL-Farraj, Z. (2007). Effect of Mobil Phone Use on Roads Safety in Amman. Unpublished Master Thesis, the University of Jordan.

Carr, B. (1970). A Statistical Analysis of Rural Ontario Traffic Accidents Using Induced Exposure Data. Procceding Of the Symposium on the Use of Statistical Methods in the Analysis of Road Accidents, 86-72. OECD, Paris, France.

Chen, L.H., Baker, S.P., Braver, E.R., \& Li, G. (2000). Carrying Passengers as a Risk Factor for Crashes Fatal to 16- and 17 - Year-Old Drivers. JAMA, 283(12), 1578-1582.

Fohr, S. A., Layde, P. M., \& Guse, C. E. (2005). Graduated Driver Licensing in Wisconsin: dose it create safer drivers? Wisconsin Medical Journal, 104, 31-36. Retrieved from https://www.wisconsinmedicalsociety.org/_WMS/publications/wmj/pdf/104/7/31.pdf

Global Status Report on Road Safety (2015). Geneva: World Health Organization. Retrieved from http://www.who.int/violence_injury_prevention/road_safety_status/2015/en/.

Hing, J. Y. C., Stamatiadis, N., \& Aultman-Hall, L. (2003). Evaluating the Impact of Passengers on Safety of Older Drivers. Journal of Safety Research, 34, 343-351. Retrieved from https://pdfs.semanticscholar.org/96c7/30bd8bd04ec65ec63cf775e236a1cac5cb63.pdf

Jadaan, K., AL-Hyari, I., Naghawi, H., Ammourah, R., \& Al Nabulsi, Z. (2013). Traffic Safety in Jordan: Magnitude, Cost and Potential Countermeasures. Journal of Traffic and Logistics Engineering, 1(1), 54-57. Retrieved from https://pdfs.semanticscholar.org/99a6/97fce7d64c2fc962e63f3a911551bf7c8ffe.pdf

Jordan Traffic Institute (JTI). Traffic Accident statistics report 2015. Retrieved from http://www.psd.gov.jo/images/jti/images/studyAcc2015.pdf

Kirk, A., \& Stamatiadis, N. (2001). Crash Rates and Traffic Maneuvers of Younger Drivers. Transportation Research Record $1779 . \quad$ Retrieved from https://www.researchgate.net/publication/245559690_Crash_Rates_and_Traffic_Maneuvers_of_Young er_Drivers

Lyles, R. W., Stamatiadis, P., \& Lighthizer, D. (1991). Quasi-induced exposure revisited. Accident Analysis and Prevention, 23(4), 275-285. 
McEvoy, S. P., Stevenson, M. R., \& Woodward, M. (2007). The Prevalence of and factors associated with, serious crashes involving distracting activity. Accident Analysis \& Prevention, 39(3), 475-482.

Mengert, P. (1982). Project Memorandum: Literature Review on Induced Exposure Models. Task 2. (1982). HS-270 PM-223-US-4A. Cambridge, MA: US DOT, TSC.

Naghawi, H. (2018). Negative Binomial Regression Model for Road Crash Severity Prediction. Modern Applied Science, 12(4), 38-48. $\quad$ Retrieved from http://www.ccsenet.org/journal/index.php/mas/article/view/73852/40924

Naghawi, H. (2017). Young Drivers' Safety in Jordan. Transportation Research Board 96th Annual Meeting Transportation Research Board. Washington, DC.

National Highway Traffic Safety Administration. (2010). Traffic Safety Facts: Young Drivers, DOT HS 809 336, Washington, DC.

OECD-ECMT. (2006). Young Drivers: the Road to Safety. Paris Organization for Economic Co-operation and Development OECD; European Conference on Ministers of Transport ECMT. Transportation Research Center, 2006. Retrieved from http://www.oecd.org/itf/37556934.pdf

Online Sample Size Calculator. Retrieved from http://www.surveysystem.com/sscalc.htm

Preusser, D. F., Ferguson, S. A., \& Williams, A. F. (1998). The Effect of Teenage Passengers on Fatal Crash Risk of Teenage Drivers. Accident Analysis \& Prevention, 30(2), 217-222.

Regan, M., Young, K., \& Hammer, M. (2003). Driver Distraction. A Review of the Literature, Monash University Accident Research Centre. Victoria. Retrieved from https://www.monash.edu/_data/assets/pdf_file/0007/217177/muarc206.pdf

Rice, T. M., Peek-Asa, C., \& Kraus, J. F. (2003). Nighttime Driving Passenger Transport, and Injury Crash Rates of Young Drivers. Injury Prevention, 30, 245-250. Retrieved from https://www.ncbi.nlm.nih.gov/pmc/articles/PMC1730980/pdf/v009p00245.pdf

Tefft, B., Williams, A. F., \& Grabowski, G. (2013). Teen Driver Risk in Relation to Age and Number of Passengers, United States, 2007-2010. Traffic Injury Prevention, 14(3).

Thorpe, J. T. (1967). Calculating relative involvement rates in accidents without determining exposure. Traffic Safety Research Review.

Yan, X., Radwan, E., \& Abdel-Aty, M. (2005). Characteristics of Rear-end Accidents at Signalized Intersection Using Multiple Logistic Regression Model. Accident Analysis and Prevention, 37, 983-995.

Young, K., \& Regan, M. (2007). Driver distraction: A review of the literature. In I. J. Faulks, M. Regan, M. Stevenson, J. Brown, A. Porter, \& J. D. Irwin (Eds.), Distracted driving. Sydney, NSW: Australasian College of Road Safety (pp. 379-405). Retrieved from http://citeseerx.ist.psu.edu/viewdoc/download?doi=10.1.1.469.4178\&rep=rep1\&type=pdf

\section{Copyrights}

Copyright for this article is retained by the author(s), with first publication rights granted to the journal.

This is an open-access article distributed under the terms and conditions of the Creative Commons Attribution license (http://creativecommons.org/licenses/by/3.0/). 